\title{
The Synthesis, Molecular Structures and Supramolecular Architecture of Amine Adducts of Bis(pentafluorophenyl)zinc
}

\author{
Andrew J. Mountford, Simon J. Lancaster, * Simon J. Coles, Peter N. Horton, David \\ L. Hughes, Michael B. Hursthouse and Mark E. Light \\ A series of eight adducts of the form $\left(\mathrm{RR}^{\prime} \mathrm{R} " \mathrm{~N}\right)_{2} \cdot \mathrm{Zn}\left(\mathrm{C}_{6} \mathrm{~F}_{5}\right)_{2}$ have been prepared and \\ their solid state structures determined to investigate the role of intermolecular \\ interactions involving pentafluorophenyl substituents in determining supramolecular \\ architectures. A number of both intra- and inter-molecular non-covalent interactions \\ are observed including phenyl-pentafluorophenyl stacking (I), X-H $\cdots$ F-C contacts (II) \\ and offset face-to-face contacts between pentafluorophenyl rings (III), giving rise to \\ one-, two- and three-dimensional supramolecular structures.
}




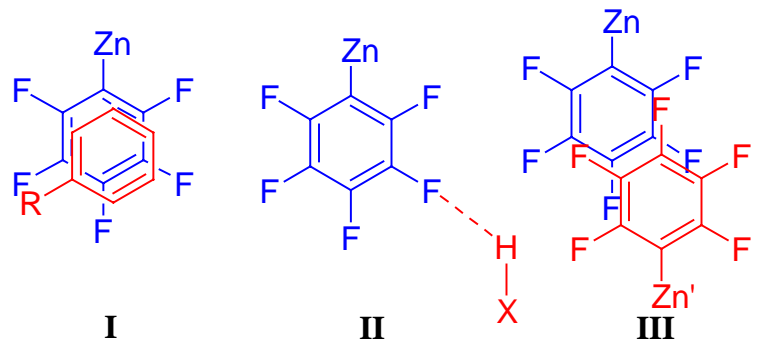

